\title{
松の実脂質の成分
}

\author{
平田芳明 $* 1$ - 関口礼司 $* 1 \cdot$ 斎藤 実 ${ }^{* 1}$-久保田紘二 $* 2$ 鹿山 光 $* 3$ \\ *1 財団法人日本食品分析センター ( 151 東京都渋谷区元代々木町 $52-1$ ) \\ $* 2$ 日本油脂株式会社王子工場, 食品研究所 (干114 東京都北区豊島 4-18-11) \\ $* 3$ 福山大学工学部食品工学科 (广792-02 広島県福山市東村町三蔵 985)
}

\section{Components of Pine Seed Lipids}

Yoshiaki Hirata*1, Reiji Sekiguchi*1, Minoru SAItoH*1, Koji Kubota $^{* 2}$, and Mitsu KAYAmA*3

*1 Japan Food Research Laboratories

(52-1, Motoyoyogi-cho, Shibuya-ku, Tokyo, $\mathbf{\top} 151)$

*2 Laboratory of Food Research, Nihon Oil and Fats Co., Ltd., Ooji Branch

(4-18-11, Toshima, Kita-ku, Tokyo, T114)

*3 Department of Food Science and Technology, Faculty of Engineering, Fukuyama University (985, Sanzo, Higashimura, Fukuyama-shi, Hiroshima-ken, ₹729-02)

Lipids extracted from three pine seeds, Pinus koraiensis, Pinus armandi and Pinus cembra, were studied for general properties, fatty acid, sterol, phospholipids, and tocopherol content and autoxidation by the AOM test.

All the lipids contained $14.7 \sim 18.6 \%$ of $\Delta$ cis -5 , cis -9 , cis-12-octadecatrienoic acid $(\Delta 5,9$, $12-18: 3$ and designated here tentatively as pinolenic acid). The content of this acid in polar lipids was considerably less than in neutral lipids. The content of pinolenic acid in 2-monoacylglycerol was very low (1.2 2.6 \%) and was thus considered distributed mainly at the 1,3-position.

Sterol composition consisted of three sterols, sitosterol, $\Delta 5$-avenasterol and campesterol. Total sterol content of lipid extracted from $P$. armandi seeds was higher than that in the other two species.

Phosphatidylcholine (PC), phosphatidyl ethanolamine (PE) and phosphatidylinositol (PI) were present as the major phospholipids.

Total tocopherol content in pine seed lipids was less than in vegetable oils having high iodine value such as soybean oil and safflower oil. Oxidative stability by the AOM test was essentially the same as that of the above vegetable oils.

\section{1 緒言}

松の実は古来中国において食用とされたばかりでな

く，その油は火傷やぜん息の治療に使用されてきた。ま た, ここ数年来, 血圧上昇抑制作用や脂質代謝に対する 影響についての研究が行われている1),2)。

松の実油にはエチレン中断型の二重結合を示す $c i s-5$, $c i s-9, c i s-12-$ オクタデカトリエン酸（ピノレン酸）が

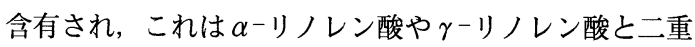
結合の相互配置が異なるため, これらの脂肪酸との代謝 連絡者: 平田芳明
上の関係や酸化安定性が注目されている。

食用の松の実として, “チョウセンゴヨウマッ” $(P i-$ nus koraiensis) について，いくつかの報告がみられる が, いずれも脂肪酸，ステロールなどのように比較的限 られた範囲について脂質のデータが示されているにすぎ な( ${ }^{3) \sim 6) 。 ~}$

そこで筆者らは “チョウセンゴョウマツ”を含むいず れも食用に供される 3 種類の松の実について, 包括的な 脂質の研究を目的として脂肪酸, ステロール, トコフェ ロールをはじめ各種の分析を行ったので，それらの結果 について報告する。 


\section{2 実 験}

$2 \cdot 1$ 試 料

試料は有限会社三松より 1990 年 8 月に恵与されたも のを用いた。“チョウセンゴョウマツ”(Pinus koraiensis) と, “ヤクタネゴヨウマツ” (Pinus armandi) はそれぞれ中国吉林省と中国四川省で採取された種 子で培せん（煎）していない生である。なお P. aramandi は採取後 2 年を経過した種子である。“オウシュ ウマツ”(Pinus cembra) はロシア(シベリア地区)で 採取されたものから圧搾法で得られた油を試料とした。

\section{$2 \cdot 2$ 分析方法}

水分 (加熱乾燥法), 脂質 (エチルエーテルーソック スレー法)，ヨウ素価 (IV)，けん化価 (SV), 不けん化物 (USM), 酸価 $(\mathrm{AV})$, 過酸化物価 $(\mathrm{PV})$, 脂肪酸組成,

リン脂質組成, トコフェロール及び AOM 試験はいず れも基準油脂分析試験法 ${ }^{7)}$ によった。中性脂質 (NL) 及 び極性脂質 (PL) の分画はシリカゲルを用い, 溶剤とし てクロロホルムとメタノールを使用して分離した。ステ ロールは金田らの方法 ${ }^{8)}$ で, 2-位置脂肪酸組成は IUPAC 法 ${ }^{9)}$ によった。樹脂成分を分析するための種子か らの脂質抽出は Folch 法 $^{10)}$ によった。

なお，P. cembraについては圧搾法で得られた油が 試料であったため極性脂質の抽出が不充分である可能性 があり, PL 及び NL の脂肪酸組成とリン脂質組成の試 験は行わなかった。

\section{3 結果及び考察}

\section{$3 \cdot 1$ 脂質, 水分及び重量}

P. koraiensis とP. armandi の脂質と水分はそれぞ れ脂質 $68.9,56.5 \%$, 水分 $2.8,5.6 \%$ であり, また種
子の平均重量は P. koraiensis が $200 \mathrm{mg}$, P. armandi は $107 \mathrm{mg}$ であった。したがってP. koraiensis の 粒の重量は約 2 倍, 脂質含量も約 $10 \%$ 高く, 両者に明 らかな差がみられた。

なお P. cembra の脂質, 水分及び種子の平均重量は 試料提供者によると, それぞれ $57.7,5.7 \%$ 及び 94 $\mathrm{mg}$ であり, P. armandiに近い值であった。

\section{$3 \cdot 2$ 脂質の一般性状}

脂質の一般性状 (Table-1) についてみると, IVは 150 前後であり, 植物油の中でもかなり高い值であっ た。SVは3 種ともほぼ同じ值であった。USM はP. armandiで他の 2 種に比べ高い值を示した。AV はP. cembra と P. koraiensis が低いものの, P. armandi はかなり高かった。これは P. armandi は採取後 2 年 を経過していたことに関係がある可能性が考えられた。 $\mathrm{PV}$ はいずれも $10 \mathrm{meq} / \mathrm{kg}$ 以下で低めであった。

\section{$3 \cdot 3$ 全脂質の脂肪酸組成}

ピノレン酸は, Table-2 に示すようにP. cembraが 最も高く P. armandi, P. koraiensis の順序であっ た。この順序は IV と同じであり, $45 \%$ 程度含まれる

Table-1 General properties of pine seed lipids.

\begin{tabular}{lccccc}
\hline $\begin{array}{l}\text { Source of } \\
\text { lipid }\end{array}$ & IV & SV & $\begin{array}{c}\text { USM } \\
(\%)\end{array}$ & AV & $\begin{array}{c}\text { PV } \\
\text { (meq/kg) }\end{array}$ \\
\hline $\begin{array}{l}\text { Pinus } \\
\text { koraiensis }\end{array}$ & 146 & 196 & 0.49 & 1.34 & 8.5 \\
\hline $\begin{array}{l}\text { Pinus } \\
\text { armandi }\end{array}$ & 151 & 195 & 0.76 & 22.1 & 5.9 \\
\hline $\begin{array}{l}\text { Pinus } \\
\text { cembra }\end{array}$ & 154 & 192 & 0.48 & 2.99 & 5.8 \\
\hline
\end{tabular}

Table-2 Fatty acid composition of pine seed lipids.

\begin{tabular}{|c|c|c|c|c|c|c|c|c|c|c|}
\hline \multirow{2}{*}{ Fatty acid } & \multicolumn{4}{|c|}{ Pinus koraiensis } & \multicolumn{4}{|c|}{ Pinus armandi } & \multicolumn{2}{|c|}{ Pinus cembra } \\
\hline & $\mathrm{TL}$ & $\mathrm{NL}$ & $\mathrm{PL}$ & $2-\mathrm{MG}$ & $\mathrm{TL}$ & NL & $\mathrm{PL}$ & $2-\mathrm{MG}$ & $\mathrm{TL}$ & $2-\mathrm{MG}$ \\
\hline $16: 0$ & 5.0 & 4.9 & 17.4 & 2.4 & 4.6 & 4.6 & 13.8 & 2.9 & 4.6 & 2.8 \\
\hline $18: 0$ & 2.3 & 2.3 & 3.7 & 1.0 & 2.0 & 2.0 & 3.3 & 1.2 & 2.4 & 1.2 \\
\hline $18: 1$ & 27.0 & 27.0 & 23.7 & 29.0 & 23.8 & 24.2 & 22.2 & 25.2 & 24.9 & 27.5 \\
\hline $18: 2(\Delta 5,9)$ & 1.9 & 2.0 & 1.0 & - & 3.8 & 3.8 & 2.8 & 0.8 & 1.4 & - \\
\hline $18: 2(\Delta 9,12)$ & 45.5 & 45.5 & 45.2 & 64.0 & 45.8 & 45.7 & 41.7 & 64.7 & 44.6 & 63.3 \\
\hline $18: 3(\Delta 5,9,12)$ & 14.7 & 14.8 & 4.0 & 1.6 & 15.8 & 15.6 & 8.5 & 2.6 & 18.6 & 2.6 \\
\hline $18: 3(\Delta 9,12,15)$ & 0.2 & 0.2 & 0.5 & 0.1 & 0.2 & 0.3 & 0.8 & 0.2 & 0.3 & 0.1 \\
\hline $20: 0$ & 0.3 & 0.3 & 0.4 & 0.1 & 0.4 & 0.4 & 0.5 & - & 0.3 & - \\
\hline $20: 1$ & 1.3 & 1.2 & 0.8 & 0.3 & 1.4 & 1.0 & 1.0 & 0.2 & 1.3 & 0.2 \\
\hline $20: 2(\Delta 11,14)$ & 0.6 & 0.6 & 0.6 & 0.3 & 0.6 & 0.6 & 0.4 & 0.3 & 0.6 & 0.3 \\
\hline $20: 3(\Delta 5,11,14)$ & 1.1 & 1.1 & 2.3 & 0.5 & 1.5 & 1.3 & 2.2 & 0.7 & 1.0 & 0.7 \\
\hline
\end{tabular}

TL : total lipid ; NL : neutral lipid ; PL : Polar lipid ; 2-MG : 2-monoacylglycerol 
Table-3 Content and composition of sterols in pine seed lipids.

\begin{tabular}{|c|c|c|c|c|}
\hline $\begin{array}{c}\text { Source of } \\
\text { sterol }\end{array}$ & Campe & $\begin{array}{l}\text { Sito } \\
(\%)\end{array}$ & $\Delta 5-$ Avena & $\begin{array}{c}\text { Total } \\
\text { sterol } \\
\text { content } \\
(\mathrm{mg} / 100 \mathrm{~g})\end{array}$ \\
\hline \multicolumn{5}{|l|}{ Pinus } \\
\hline koraiensis & 11 & 61 & 28 & $254(52 \%)$ \\
\hline \multicolumn{5}{|l|}{ Pinus } \\
\hline armandi & 9 & 70 & 22 & $343(45 \%)$ \\
\hline \multicolumn{5}{|l|}{ Pinus } \\
\hline cembra & 6 & 60 & 35 & $229(48 \%)$ \\
\hline
\end{tabular}

リノール酸が 3 種ともほぼ同じ值であることを考慮する と, ピノレン酸の含有量の相違が IV に大きく影響して いると考えられた。もう 1 つ主要な脂肪酸であるオレ イン酸はP. koraiensis が最も高い值を示した。

\subsection{NL 及び PL の脂肪酸組成}

各脂質画分により相違が際立つ脂肪酸はパルミチン酸 とピノレン酸であった (Table-2)。PL にはパルミチ ン酸が多く，ピノレン酸は極端に少なかった。一方，才 レイン酸とリノール酸は 2 つの脂質画分で顕著な差異は 認められなかった。

\subsection{2-MG の脂肪酸組成}

2-MG の脂肪酸組成は NL のそれと顕著な相違が認 められた $($ Table-2)。主要な脂肪酸では, リノール酸 の割合が高く，ピノレン酸は著しく低含量となってい る。この相違を数值化すると, NL の各脂肪酸の組成值 を 1 とした時, $2-\mathrm{MG}$ の脂肪酸組成中のリノール酸は 1.4 倍でやや高く, ピノレン酸は $0.11 \sim 0.17$ 倍と極めて 低い值示した。一方, オレイン酸は 1.0 とほとんど違 いがなかった。2-MG の脂肪酸組成のこれらの特徴は 高木ら ${ }^{3)}$ の報告と一致していた。またリノール酸のよう に不飽和度の高い脂肪酸が 2 の位置に多く結合すること

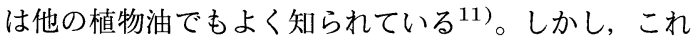
とは逆にピノレン酸が 2-位置以外に極端に多く結合し ていることは興味深い。なお， $2-\mathrm{MG}$ の脂肪酸組成に ついて, 品種による相違は認められなかった。

\section{$3 \cdot 6$ ステロール組成}

松の実の主要なステロールはシトステロール (Sito), $\Delta 5$-アベナステロール ( $\Delta 5$-Avena) 及びカンペステ ロール (Campe) であった。P. armandi のステロール の総量は他の 2 種より $100 \mathrm{mg} / 100 \mathrm{~g}$ 前後高く, 差異が 認められた (Table-3)。

各ステロールの割合も P. armandi は Sito が $70 \%$ と高く, 他の 2 種は $60 \%$ 程度と差が認められた。一 方, $\Delta 5$-Avena は $P$. armandi が他の 2 種より低く,
Table-4 Phospholipid composition of pine seed lipids ( $\mathrm{mg} / 100 \mathrm{~g})$.

\begin{tabular}{lccccc}
\hline $\begin{array}{l}\text { Source of PL } \\
\text { PC }\end{array}$ & PE & PI & Others & Total \\
\hline $\begin{array}{l}\text { Pinus } \\
\text { koraiensis }\end{array}$ & 690 & 240 & 110 & 140 & 1,180 \\
\hdashline $\begin{array}{l}\text { Pinus } \\
\text { armandi }\end{array}$ & 171 & 85 & 47 & 78 & 381 \\
\hline
\end{tabular}

Table-5 Content of tocopherols in pine seed lipids and AOM test.

\begin{tabular}{llc}
\hline $\begin{array}{l}\text { Source of } \\
\text { lipid }\end{array}$ & $\begin{array}{l}\text { Content of tocopherols }(\mathrm{mg} / 100 \mathrm{~g}) \\
\text { Total }(\alpha-\beta-\gamma-\delta-)\end{array}$ & AOM time $(\mathrm{h})$ \\
\hline $\begin{array}{c}\text { Pinus } \\
\text { koraiensis }\end{array}$ & $30.7(14.8, \mathrm{tr}, 15.9, \mathrm{tr})$ & 8.5 \\
\hdashline $\begin{array}{l}\text { Pinus } \\
\text { armandi }\end{array}$ & $37.5(14.8, \mathrm{tr}, 22.7, \mathrm{tr})$ & 14.0 \\
$-\begin{array}{c}\text { Pinus } \\
\text { cembra }\end{array}$ & $31.9(18.2, \mathrm{tr}, 13.7, \mathrm{tr})$ & 8.0 \\
\hline
\end{tabular}

AOM time : The time until peroxide value reached $100 \mathrm{meq} / \mathrm{kg}$ at $97.8^{\circ} \mathrm{C}$, tr : less than $0.1 \mathrm{mg} / 100 \mathrm{~g}$

Sito と逆の傾向が認められた。Jeong のP. koraiensis についての報告5) とステロール総量及び各ステロールの 組成はよく一致した。なお, USM 中のステロール量は いずれの品種も $50 \%$ 前後を示し, 品種間の相違は認め られなかった。

\section{$3 \cdot 7$ リン脂質組成}

P. koraiensis のリン脂質組成は $\mathrm{PC}$ が最も多く, PE と PI がそれに続く割合であった (Table-4)。この 傾向は Wagner らの報告 ${ }^{12)}$ と PC が最大の成分である 点においては一致しているが, PI がそれに続く成分と いう点では相違していた。

$P$. armandi の各リン脂質量は $P$. koraiensis と同様 に $\mathrm{PC}>\mathrm{PE}>\mathrm{PI}$ の順序であるが, それぞれの含量は $P$. koraiensis に比べ著しく低い值であった。これは $P$. armandi の AV が 22.1 と高いことから, リン脂質加 水分解が進行している可能性が考えられた。

\section{8 トコフェロール量及び AOM 試験}

トコフェロール (Toc) はいずれの品種も $\alpha$-Toc と $\gamma$ -Toc が主成分であった $($ Table-4)。 $\alpha$-Toc と $\gamma$-Toc の量的な関係は P. koraiensis はほぼ等しく, P. cembra が $\alpha$-Toc $>\gamma$-Toc, 逆にP. armandi は $\alpha$-Toc $<\gamma^{-}$ Toc という結果であった。

同族体の中で酸化防止力が高いとされる $\gamma$-Toc を $P$. armandi が多く含有することと, 3 品種の中での AOM 
時間が最長であったことが関連している可能性が考られ た。ピノレン酸は特殊な二重結合の配置により, 活性メ チレン基が 1 つだけしか存在しない点で, 酸化安定性の 面でも注目されている。3つの品種共に総 Tocは 30 $\mathrm{mg} / 100 \mathrm{~g}$ 台で, 他の植物油に比較する之少ない方に属 し13), IV が大豆油, サフラワー油より高いにもかかわ らず，その $\mathrm{AOM}$ 值は 8 14 h を示し，大豆油，サフ ラワー油の AOM 時間 $(7.5 \sim 16.5 \mathrm{~h})^{14)}$ と大きな差は認 められなかった。

本報告の要旨は第 29 回油化学討論会・油化学研究発 表会（平成 2 年 10 月 17 日，仙台市）において発表し た。

終わりに, 本研究に当たり試料を提供して頂いた(有) 三松の吉原将純氏に深謝します。

〔平成 5 年 (1993 年) 12 月 22 日受理〕

\section{文献}

1）池田郁男, 若松康三郎, 菅野道廣, 第 46 回日本栄養 食糧学会講演要旨集 p. 47 (1992)

2) 村田昌一, 井出 隆, 菅野道廣, 第 46 回日本栄養 - 食 糧学会講演要旨集 p. 27 (1992)

3) T. Takagi, Y. Itabashi, Lipids, 17, 716 (1982)
4) T. M. Jeong, T. Itoh, T. Tamura, T. Matsumoto, Lipids, 9, 921 (1974)

5) A. Seher, M. Maria, T.S. Ko, Fette Seifen Anstrichm., 79, 203 (1977)

6) TH. Yoon, KJ. Im, E.T. Koh, JS. Ju, Nutrition Research, 9, 357 (1989)

7) 日本油化学協会編, “基準油脂分析試験法” 1.1.5.2 a-83 ; 1.1.3.3-71 ; 2.4.5.1-71；2.4.3.1-71；2.4.1-83 ; $2.4 .12-86 ; 2.4 .20 .2-77 ; 2.4 .21 .2-73 ; 5.3 .3 .1-86$; $2.4 .31-86 ; 2.4 .28 .1-81$

8) T. Kaneda, A. Nakajima, K. Fujimoto, T. Kobayashi, S. Kiriyama, K. Ebihara, T. Innami, K. Tsuji, E. Tsuji, H. Shinma, J. Nutr. Sci. Vitaminol., 26, 497 (1980)

9) Standard Methods for the Analysis of Oils, Fats and Derivatives (IUPAC) 2. 210

10) J. Folch, M. Lees, G.H.S. Stanley, J. Biol. Chem., 226, 497 (1957)

11) F.H. Mattson, J. Lipid Reserch, 4, 392 (1963)

12) H. Wagner, P. Wolff, Fette Seifen Anstrichm., 66, 425 (1964)

13) A.P. Carpenter, J. Am. Oil Chem. Soc., 56, 668 (1979)

14）阿部芳郎, “油脂・油糧ハンドブック”幸書房 (1988) p. 333 